\title{
Assessing the South Korean Model of Emergency Management during the COVID-19 Pandemic
}

\section{Min-Hyu Kim , Wonhyuk Cho, Hemin Choi \& Joon-Young Hur}

To cite this article: Min-Hyu Kim , Wonhyuk Cho , Hemin Choi \& Joon-Young Hur (2020)

Assessing the South Korean Model of Emergency Management during the COVID-19 Pandemic, Asian Studies Review, 44:4, 567-578, DOI: 10.1080/10357823.2020.1779658

To link to this article: https://doi.org/10.1080/10357823.2020.1779658

\section{Published online: 02 Jul 2020.}

6 Submit your article to this journal

\section{Џll Article views: 1338}

Q View related articles $\square$

$\bigodot_{\text {crosshark }}$ View Crossmark data $\longleftarrow$

它

Citing articles: 1 View citing articles $₫$ 


\title{
Assessing the South Korean Model of Emergency Management during the COVID-19 Pandemic
}

\author{
Min-Hyu Kim (D) ${ }^{1}$, Wonhyuk $\mathrm{Cho}^{2}$, Hemin $\mathrm{Choi}^{3}$ and Joon-Young Hur ${ }^{4}$ \\ ${ }^{1}$ Arizona State University and Hainan University; ${ }^{2}$ Victoria University of Wellington; ${ }^{3}$ Seoul National \\ University; ${ }^{4}$ Korea Institute of Public Administration
}

\begin{abstract}
The COVID-19 pandemic has led to an unprecedented global public health crisis, and governments have implemented various responses with varying degrees of effectiveness. South Korea's approach, which has involved minimal lockdown in order to "flatten the curve", and which offers an alternative for many democracies, has attracted much attention. Based on in-depth interviews with public health professionals and policy advisors in government agencies, this article analyses how well South Korea's response to COVID-19 complies with the expectations of good governance, and assesses the strengths and challenges of the Korean model. Our analysis shows that South Korea has been reactive rather than preventive/passive amid waves of clusters such as outbreaks in nightclubs, e-commerce warehouses, schools, hospitals and religious gatherings. The government has used a range of countermeasures, including contact tracing, diagnostic testing, media briefings and text alerts. At the same time, the challenges for the Korean approach have been concerns about privacy, fatigue over emergency alerts and politicisation.
\end{abstract}

\section{KEYWORDS}

Pandemic; public health; good governance; COVID-19; emergency management; South Korea

\section{Introduction}

The outbreak of the 2019 novel coronavirus (hereafter COVID-19) is no longer merely a conundrum for a certain number of countries or regions, but rather an emergency across the world. In March 2020, South Korea was considered to be the second-most seriously affected country, but just three months later it was one of only a handful of countries where the spread had been curtailed to less than 80 new cases per day. By contrast, a number of countries were reporting exponentially rising numbers of confirmed cases, which were overwhelming their healthcare systems (Weible et al., 2020). By the end of May, when this commentary was completed, the pandemic appeared to be under control in South Korea, despite the outbreak of some cluster transmissions in nightclubs and e-commerce logistics facilities. These outbreaks did not lead to mass infections, although South Korea was still seeing new patients daily.

A distinguishing feature of the "Korean model" of emergency management was that it did use restrictive nationwide lockdowns, and draconian control of people's movements, to "flatten the curve". The government's response to COVID-19 was heralded as an example 
of how democracies might contain the spread of the virus, while keeping the economy largely open. Many Western democracies have struggled to curtail the spread, but doing so need not come at the cost of democratic freedoms, as South Korea has shown. Meanwhile many non-democracies, such as Russia and Belarus, have struggled to contain the virus. Analysing the case of South Korea illustrates that democracies can handle the pandemic, and that there is a democratic alternative to China's restrictive treatment of COVID-19. South Korea, we show, used its strengths of openness, transparency and the free flow of information as a liberal democracy to address the pandemic crisis without sweeping stay-at -home orders or forced quarantine. South Korea is not the only democracy with the capacity to flatten the curve of virus transmission, as countries such as New Zealand, Australia and Norway have done so too. It is, however, the largest democracy to bend the curve by more than 95 per cent from its peak in February 2020. Furthermore, if we consider its geographical proximity to China and the huge volume of people movements between China and South Korea, the Korean case is noteworthy.

This article uses an adaptive governance framework to illustrate the inner workings of South Korea's model of crisis management during its response to the pandemic. We assess how the government responded to the challenges of the crisis through scientific learning, public learning, responsiveness and representation, and we identify the shortcomings and areas for improvement in the Korean model. In addition, we identify the elements of "good governance" in this model of crisis management. The empirical basis for our analysis is in-depth interviews with seven public health professionals and policy advisors in the Korea Centers for Disease Control and Prevention (KCDC), the Ministry of Food and Drug Safety, the National Disaster Management Research Institute, the Korea Institute of Public Administration and the Seoul Institute. We obtained Institutional Review Board (IRB) approval for the interviews used in this study, as well as for the questionnaire and consent form that were provided to participants (IRB ID: STUDY00011953). The interviews were conducted in the Korean language, and the consent form and interview questionnaires were written in both Korean and English.

\section{The COVID-19 Outbreak in South Korea and the "Super-spreader" Problem}

In December 2019, the World Health Organization (WHO) was informed that an unknown strain of pneumonia had been identified in Wuhan, China. South Korea reported its first confirmed case, a 35-year-old Chinese woman, on 20 January 2020. In late January the virus' Ribonucleic acid sequence, which is used for diagnostic tests, was released, and in February, the KCDC approved a diagnostic kit developed by a Korean company.

From February, when everything seemed to be initially under control, things went wrong quite quickly: a "super-spreader" appeared as a carrier, and was found to have attended mass congregations at the Shincheonji ("New Heaven and Earth") Church in the city of Daegu. The super-spreader transmitted the virus to her fellow worshippers as well as other unsuspecting residents of Daegu. The number of COVID-19 cases in South Korea multiplied exponentially in the next two weeks, and the government's response swung into full operation in late February and early March. 
Throughout April, South Korea experienced an ongoing and steady recovery. As of early May, South Korea had reduced to single digits the number of new daily cases, from their peak in February of more than 900 per day. Amid a continued downward trend in new cases, on 6 May the government relaxed social distancing rules to "distancing in daily life" so that citizens could return to work as well as visit shops, parks and restaurants.

As experts urged vigilance, a new cluster of infections began in nightclubs in the Itaewon entertainment district in Seoul, in early May. The Itaewon cluster had more than 250 cumulative confirmed cases by the end of May. Contact tracing was more difficult in responding to the nightclub outbreak, as many of the affected clubbers were hesitant to identify themselves due to social stigma. So health authorities had insufficient information to track this new outbreak. New clusters also erupted in e-commerce warehouses, hospitals and schools. However, overall, the new waves did not seem to generate widespread transmission of the virus, and the number of confirmed new cases daily was fewer than 30 to 40 for the early weeks in May, until the number of e-commerce warehouse cases spiked to 80 . The case of South Korea suggests that "defeating" COVID-19 is not simple or quick, as new waves were emerging even as one of the best-performing countries relaxed restrictions on people's movements.

\section{Adaptive Governance: Theoretical Framework}

Adaptive governance is defined as flexible and learning-based multi-level modes of governance or institutional arrangements that can build resilience for the challenges posed by complex and urgent problems (Brunner et al., 2005; Chaffin et al., 2014; Chaffin \& Gunderson, 2016; Folke et al., 2005). Adaptive governance is expected to improve the public interest through more resilient structures, which in turn lead to appropriate policy changes (Hong \& Lee, 2018). Coordinating agencies, often in central or federal governments, must have the ability to deal with challenges in four domains: scientific learning, public learning, responsiveness and representation (Andrew \& Kendra, 2012; Scholz \& Stiftel, 2010).

Research on adaptive governance has expanded from ecosystem management to emergency management and other areas of public policy (Holling \& Gunderson, 2002; Ostrom, 1999). For example, Andrew and Kendra (2012) analysed disaster-related behaviour in health services using an adaptive governance framework, and emphasised the ability to continuously adjust administrative procedures and boundaries. The adaptive governance framework is suited to dealing with problems that are complex, uncertain and in which multi-level government agencies should be involved (Nelson et al., 2008). Given that the core value of the adaptive governance framework is learning (Janssen \& van der Voort, 2016), in this article we consider South Korea's experience with the Middle East Respiratory Syndrome (MERS) outbreak in 2015 to be an important context for our analysis of the COVID-19 pandemic. 


\section{Learning, Responsiveness and Representation}

\section{Scientific learning: Contact-tracing and diagnostic testing capabilities}

In public health emergencies, governments demand a certain level of scientific expertise as they search for certainty when they are forced to choose between different responses (Weible et al., 2020). In the context of an emergency, however, scientific learning is complicated as policymakers need to have prescriptions readily available within a short space of time, while scientists require substantial time to validate knowledge.

In a pandemic, the collection of reliable scientific data largely depends on the capabilities of diagnostic testing. Out of a total population of 50 million, South Korea tested more than 600,000 people after the first outbreak in January, and had a daily capacity for more than 15,000 tests. An appropriate supply chain for manufacturing diagnostic test kits was crucial to the expansion of testing capability, and as such in January the government began to coordinate with the biotech industry to provide a sufficient quantity of test kits. An interviewee who works in the Korea Centers for Disease Control described this process:

The KCDC disclosed their diagnostic technologies to private sector manufacturers, and supported them by expediting critical independent reviews by the Ministry of Food and Drug Safety. This allowed policymakers to implement a real-time response system based on large volumes of testing data, where the whole process for each test result took only six hours.

Another interviewee, from the Ministry of Food and Drug Safety, explained how the government and pharmaceutical companies used the Emergency Use Authorisation (EUA) to leverage scientific learning: "Occasionally, a request for Emergency Use Authorisation approval comes in on Friday nights and the Ministry of Food and Drug Safety staff go to work to review documents in advance on the Saturday".

"Field epidemiologists", or Epidemic Intelligence Service (EIS) officers, acted as "street-level" scientists and were responsible for processing test-kit data. These officers needed to have extensive practical experience, with a minimum of two years of training in field epidemiology programmes. Once test-kit results arrived at local public health centres, field epidemiologists immediately reviewed them, because the timely processing of results was critical to accurately understanding the condition of patients. A one-click process made it possible to review all the information about affected people within about 10 minutes. EIS officers were authorised to access transaction data from credit card companies and subscriber location information from mobile-phone carriers, using a onestop big-data system. By contrast, under the previous system EIS officers had to request formal approval from the police and the Credit Finance Association in order to get this information. Given the extent of their powers, field epidemiologists were even referred to as "epidemic detectives". Their investigations and assessments identified the confirmed cases' clusters, which in turn informed follow-up decisions on who needed to be reached for further diagnoses, and who would be subjected to quarantine measures.

With the lessons learned from the MERS pandemic, South Korea's field epidemiologists contributed to the government's ability to respond to the COVID-19 outbreak due to their extensive investigatory powers. After the MERS outbreak, the Infectious Disease 
Control and Prevention Act was revised in June 2015 to increase the number of field epidemiologists, strengthen the authority of field epidemiologists and give them the necessary security clearances for accessing and disclosing extensive information on the spread of diseases. Before the revision of the act, during the MERS outbreak, field epidemiologists had a very limited role and insufficient legal authority. Another change after 2015 was that all local government authorities in South Korea were required to hire at least one medical doctor as a field epidemiologist. It was challenging for local government authorities in rural areas to attract highly qualified field epidemiologists, due to their inability to offer competitive salaries, but continued efforts were made to comply with this requirement across the country.

Despite South Korea's overall positive outcome in pursuing an evidence-based response, scientifically driven advice was occasionally moderated by other considerations, such as the pandemic's impact on small business and employment. For example, in respect to the new outbreaks, public health experts had previously communicated their concerns over easing social distancing rules and about future outbreaks in bars and clubs. Experts found that younger citizens cared less about the health risks of infectious diseases, based on a survey in February 2020, which indicated that the 18-39 age group had a higher tolerance for these risks, compared to people aged 40 and older (You, 2020). Policymakers took the advice of health experts seriously, but the government decided to give more weight to the advantages of reopening the economy, including bars and pubs. According to an interviewee affiliated with the Seoul Institute:

Public health experts were worried about new waves, and there was the strong opinion among us that it was too early to relax social distancing rules on 5 May 2020, but the government authorities had a firm stance for shifting to the relaxed "distancing in life" mode. There was an awareness in expert communities that a second wave could come from pubs or nightclubs.

Overall, South Korea's response to the pandemic was reactive rather than preventive or passive. Its approach was based on the government's confidence in the capacity of the public health system to rein in the transmission of the virus if new waves occurred. This response was in keeping with the "developmental state" tradition and the legacy of state intervention, which has persisted in South Korea despite democratic and neoliberal reforms in recent decades (Hundt, 2015; Weiss \& Thurbon, 2020).

\section{Public learning: Informative media briefing and alert texting}

A pandemic crisis creates the need for a government to provide sufficient information to the public, as well as to convince citizens that its countermeasures are based on scientifically reasoned decisions (Cairney, 2016; Weible et al., 2020). Health authorities should communicate the consequences of actions, the reasons for restrictions and the alternatives for reducing harm (Scholz \& Stiftel, 2010).

South Korean governments have not always been straightforward with respect to contact-tracing and disclosing information to the public, but during the COVID-19 pandemic the government announced it would take a new approach. That is, it would keep the public fully informed. For example, most of the information shared with the media was the 
same as that prepared for ministerial briefings, so that the public and policymakers had almost the same level of understanding. In press conferences, epidemiology specialists were present to answer technical questions, and another legacy of the MERS outbreak was that the experts and bureaucrats were better able to provide a broad range of technical information, in a way that the media and the public could understand and use.

These public-learning efforts were partly a result of the costly lessons learned during the MERS outbreak, when the government failed to share information with the public. This failure was found to have worsened the spread of MERS. For example, hospital outbreaks were unknowingly the major cause of transmission of MERS, but government officials did not release hospital information because they were allegedly afraid of the financial fallout if private hospitals were shut down. The MERS experience led to the government being considerably more sensitive to the danger posed by not sharing relevant information. After the MERS outbreak, public-disclosure provisions were added to the Infectious Disease Control and Prevention Act.

The government's understanding of the political consequences of failures in disaster management also informed its willingness to adopt public-learning measures. On 16 April, the government stated that the COVID-19 countermeasures were based on lessons learned from the Sewol ferry disaster in 2014. That disaster was a notable example of publiclearning failure, and it sparked a political movement to impeach the then-president. An interviewee who is affiliated with the National Disaster Management Research Institute noted: "Disaster management became more focussed on social (man-made) disasters after the Sewol ferry disaster, while beforehand the efforts had been more concentrated on natural disasters. COVID-19 will have political importance in the post-pandemic era".

The government launched a COVID-19 information portal, which provided factcheckers and promoted countermeasures such as "social distancing rules" or "distancing in daily life". The public could see real-time data updates on the spread of the virus, as well as how the government was responding to it at the regional, national and international levels. The health ministry sent numerous real-time messages via social media and major search engines.

Text message alerts were an important part of public learning. People with smartphones registered with the national carrier networks received location-based alerts when they were near a confirmed case of COVID-19. Emergency text messages included all the routes taken by infected patients with a list of shops, restaurants, bars, hotels and churches, and approximate times of their visits. This enabled people who had been infected to come forward for testing, and reminded the public to pay more attention to social distancing.

\section{Responsiveness: Use of Emergency Powers, drive-through stations and face masks}

A defining feature of South Korea's response to COVID-19 was its prompt action. When the COVID-19 genetic sequence was published in January, the biotech industry (and the government) began developing and stockpiling diagnostic test kits. The KCDC established an Emergency Use Authorisation (EUA) process, which enabled it to pre-approve diagnostic test kits while minimising bureaucracy and maximising responsiveness. 
A testing kit was approved for use on 4 February, and after only six days the KCDC enacted the EUA process, as an interviewee affiliated with the KCDC explained: "The KCDC gathered pharmaceutical companies in the Seoul Train Station to communicate the urgent need, and to ask for collaboration in creating appropriate supply chains for the kits. The government 'greenlighted' an expedited approval process".

The EUA was legislated to allow for early diagnosis of infectious diseases after the MERS outbreak in 2015, and was first enacted when the Zika virus spread in 2016. It also allowed for using unapproved in-vitro diagnostic kits during serious public health emergencies. The bureaucracy had often been a roadblock to increasing Korea's testing capability during epidemic emergencies, and the government needed to strike a balance between providing the necessary level of oversight for accurate testing results and maintaining responsiveness by making the test kits available. When the COVID-19 outbreak was deemed serious due to the "super-spreaders", South Korea already had the capability to quickly and safely perform up to 15,000 diagnostic tests per day, in facilities such as drive-through testing stations and phone-booth-style walk-through facilities.

These actions were possible thanks to a decision-making mechanism that was in place, centred on the Central Disaster and Safety Countermeasures Headquarters (hereafter Central Disaster Headquarters). This was another legacy of the MERS outbreak: the Act on the Management of Disasters and Safety was revised in 2017 to establish more coordinated whole-of-government action. Another rationale for revising the Act after the MERS outbreak was to position the Prime Minister as the head of the Central Disaster Headquarters during serious national disasters such as the COVID-19 pandemic (Section 2 of the Act). South Korea has a presidential system of government, but placing the Prime Minister as the head of the disaster countermeasures headquarters had strong symbolic meaning. It allowed the Prime Minister to coordinate the actions of cabinet ministers, and for the government to take timely countermeasures during emergencies. An interviewee affiliated with the Ministry of Food and Drug Safety described the symbolism as follows:

As the ministers, deputy ministers, mayors and governors report to the Prime Minister in the Central Disaster Headquarters, the situation can be monitored every morning ... The effect would have been much weaker if the KCDC director or the Minister of Health and Welfare [instead of the Prime Minister] gave guidance on the spot.

The executive office of the President (the Blue House) decided to ration and place price controls on face masks, in order to respond to the shortage of particulate-filtering facepiece respirators. Economists were sceptical about rationing because a socialised medicine approach had rarely been used in South Korea (Schwak, 2016). But the government made this decision so that the public could purchase face masks at affordable prices, and it worked. The government limited the price of face masks to below market rates (about $\$ 1.20$ each). The Health Insurance Review \& Assessment Service used integrated pharmacy health data to monitor the distribution of masks. A whole-of-government approach was taken to monitoring the supply chain for face masks. For example, the Ministry of Food and Drug Safety monitored more than 100 manufacturing plants across South Korea, to prevent the smuggling of face masks overseas. As an interviewee affiliated with the Ministry of Food and Drug Safety explained: 
Our central investigation team and general staff were put to monitor mask smuggling on the spot, although they first thought the police were going to crack down on the mask smuggling ... Some employees were grabbed by the collar by retailers, and police officers sometimes came to smuggling sites.

In regard to responsiveness in contact-tracing, the government needed new approaches since the contact information of many of the Itaewon clubbers was missing or not found. So the government used data from cellular signal towers, anonymous testing, credit card statements and security camera footage. As such, digital technology played a big part in tracing people affected by the Itaewon club cluster. Data from signal towers provided the location of the mobile phone users, by analysing their history of accessing particular base stations. Three mobile carriers, Korea Telecom, SK Telecom and LG Telecom, collected information about subscribers who accessed the signal towers around Itaewon between 24 April and 6 May. The location of the affected subscribers could be comprehensively traced because there are signal tower base stations all over Itaewon. Seoul City and the KCDC sent text messages to more than 10,000 people who were identified through the signal tower data to have been in and around Itaewon in the relevant time period. As part of the anonymous testing regime, people only had to provide their phone numbers, rather than their full names, when undergoing diagnostic testing for the Itaewon cluster. Anonymous testing reduced the risk of asymptomatic patients spending time in their communities without being quarantined. The number of people who were tested doubled in this period because there was no pressure to disclose their names. Credit card statements allowed public health authorities to trace the transactions of more than 500 people, to complement the mobile phone data. Health authorities and the police investigated all security camera footage, both in the nightclubs and on the surrounding streets, and tracked people who moved from bars to subway stations. South Korea has two security cameras per 100 citizens (Baltrusaitis, 2020), which added to its capacity to locate people who may have contracted the virus. ${ }^{1}$

\section{Representation: Local headquarters and decentralisation}

The COVID-19 outbreak caused significant representational issues in South Korea, as more and more citizens expressed concern about the government's measures to slow the spread. For example, after the dramatic surge in the number of coronavirus cases in Daegu, there were uneven levels of harm done to residents of the city. The local government came under great pressure and scrutiny as a result. There were serious problems, such as a shortage of certified face masks, and a limited number of hospital beds, and hospitals struggled to provide sufficient negative pressure isolation rooms and intensive care units. This uneven impact from the virus sparked outcry about the measures imposed. Some citizens asked whether it was necessary to shut down Daegu, and why some patients in Daegu could not be sent to hospitals in other cities.

Emergencies create challenges in determining who should be represented in managing disasters (Scholz \& Stiftel, 2010) and the COVID-19 pandemic was no exception. There were serious disagreements in South Korea about which individuals or groups should be subjected to certain measures, and about who would determine what resources were 
used, for whom and with what authority (see Chaffin et al., 2014). An interviewee who works for the National Disaster Management Research Institute described the representational challenges and complex central-local government tensions in resource allocation as follows:

Seoul City government was able to pay out from its reserve fund during the Itaewon nightclub cluster, although the cost of anonymous testing was very expensive. However, other regional level governments do not have the financial capacity to perform anonymous testing... Local governments are on the frontline, but the central government is often asked to be accountable when disasters happen.

In the democratic ideal, all citizens have an equal right to play a role in decision-making, although this principle is often overlooked in actual emergencies (Andrew \& Kendra, 2012). The practical reason to advocate representative decision-making is that greater representation can make it easier to get the resources needed to respond to emergencies. Representation may be particularly significant in South Korea, where democratic legitimacy has been primed to justify state actions (Hundt, 2015).

The outbreak of COVID-19 created different challenges for each part of South Korea, not only in the worst affected Daegu but also in Gyeonggi Province and Seoul, where almost half of the population resides. Countermeasure headquarters were established at the city and provincial levels in order to manage the disaster in each jurisdiction. In late February the central government also announced that local governments would play a critical role in responding to the crisis, and requested that mayors and governors contribute to South Korea's overall capacity-building for emergency management.

Representing the concerns of the residents of the worst hit cities and provinces, some mayors and governors reacted more aggressively than the central government. Their quick responses helped alleviate the concerns of residents in their regions. Local representation contributed to trust building in emergency governance, due to the belief that at least someone - either at the centre or locally - was representing the concerns of citizens. An interviewee who works for the Ministry of Food and Drug Safety noted: "The cooperation between central and local government was satisfactory. The central government secured and provided resources, while local governments closely and systematically monitored local demand".

Further, the Ministry of Food and Drug Safety granted exemptions to local governments from import requirements, as historically they could not directly import medical supplies from other countries. For example, the demand for non-contact electronic thermal scanners exploded, and local governments demanded a stable supply. An interviewee who works for the Ministry of Food and Drug Safety reported that:

The Ministry of Food and Drug Safety minimised the import requirements for thermal scanners, allowing local governments to import them directly from overseas companies ... thermometer factories overseas began to operate in April and there were thermal scanners available out there.

Policy ideas from local government also increased. For instance, the governments of Seoul City, Gyeonggi Province and Gyeongnam Province called for the introduction of a universal basic income, which they labelled "anti-disaster basic income". Goyang City, to the north of Seoul, introduced drive-through testing stations, and this was benchmarked 
nationally as well as internationally. Gijang-gun district had one of the highest percentages of elderly people in South Korea, with 51.3 per cent of local residents $(30,000$ people) being at least 65 years of age. The district government directly distributed filtration face masks for free to senior citizens, and this distribution model for the elderly was emulated by other regional and local governments.

\section{Assessing the South Korean Model}

Our analysis of South Korea's response to the pandemic indicates that elements of good governance were evident, and can be explained through four aspects of the adaptive governance framework. In scientific learning, South Korean policymakers generally listened to experts. With few exceptions, the government made evidence-based decisions and collected the data it needed through widespread diagnostic tests. The government overcame the challenges of public learning by providing sufficient information to the public on COVID-19 cases through aggressive contact tracing and alerts. The government's responsiveness coordinated the collective reaction of public health experts, thereby giving them more flexibility and discretion in the field to trace contacts via digital technologies. And in terms of representation, local and regional headquarters played a significant role in amplifying the voices of residents in different parts of South Korea. The hallmark of the Korean model can be summarised as reaction rather than passivity or prevention, and this seems to be a legacy of the interventionist developmental state (Hundt, 2015). The South Korean response also underscores that the state often requires domestic enablers in order to take decisive action (Weiss \& Thurbon, 2020).

The nationalised healthcare system was an important contextual factor for widespread testing, free treatment and contact tracing of predictive cases. This single-player healthcare system allowed all (limited) medical resources to be fairly allocated for free or at low cost. South Korea has the highest annual number of patient consultations per doctor (16.6), compared to an OECD average of only seven (OECD, 2020). Our interview participants all said that the nationalised healthcare system and the affordability of medical services were unique to South Korea, and public health authorities in other countries may need to consider this if seeking to adopt Korean practices.

Despite the elements of good governance evident in South Korea's response to the pandemic, some caveats are warranted. With respect to scientific learning, there was some evidence of "groupthink", or the tendency for conformity to inhibit critical analysis (Janis, 1972), among Korean health experts. In public learning, there was a trade-off between the transparent disclosure of information and public concern that emergency alerts would divulge personal information when assembling contact-tracing results. Some analysts also worried that the accumulated fatigue of receiving text messages might reduce the willingness of citizens to be tested and to practise social distancing. Responses by local governments, meanwhile, can create impulsiveness and lead to overspending, possibly resulting in a significant increase in public debt. Emergency measures instituted by some local governments may result in the politicisation of the pandemic response, and citizens might begin to prioritise short-term gains over long-term benefits. 
The apparent trade-off between the tracking of the epidemic and privacy concerns raises the question of why privacy has not hitherto been a serious concern in South Korea. For example, 93.5 per cent of the people who were ordered to self-quarantine, such as inbound travellers, installed the government app (developed by the Ministry of Interior and Safety) on their smartphones, thereby allowing public authorities to monitor them. People who defied quarantine rules also had to wear location-tracking bracelets. South Koreans seemed to tolerate these privacy infringements during the pandemic. The Foreign Minister stated, for instance, that "Surveillance is not quite the term that I would use in tracing which is absolutely necessary to track down the patients and the close contacts in order to preserve the freedom of movement of the rest of the society" (cited in Yang, 2020). The ruling Democratic Party's victory in the legislative elections in April was interpreted as an endorsement of the government's response to the pandemic, with the highest turnout in three decades. In other words, most South Koreans seemed to think that the measures used to contain and respond to the spread of the virus were appropriate, despite their concerns about privacy. The 2015 outbreak of MERS, which infected 186 people in South Korea and resulted in 36 deaths, seemed to produce a social consensus in favour of tolerating some violations of privacy during an emergency. This in turn resulted in the revision of the Infectious Disease Control and Prevention Act in 2016, which allowed the authorities to conduct extensive tracking.

This commentary has only provided an initial analysis of the South Korean model, and it was written when the country was still seeing new patients on a daily basis. Further studies, based on in-depth analysis, are needed to assess the measures used to handle this particular pandemic, and the potential for adaptive governance to be used in overcoming future emergencies.

\section{Notes}

1 The countries with the most cameras per person are the US ( 15.3 for every 100 individuals), followed by China (14.4), the UK (7.5), Germany (6.3), the Netherlands (5.8), Australia (4), Japan (2.7), Vietnam (2.7) and France (2.5), and then South Korea (2).

\section{Acknowledgements}

All errors are the responsibility of the authors.

\section{Funding}

The contributions made by Hemin Choi and Wonhyuk Cho were partially supported by the National Research Foundation of Korea (NRF-2017S1A3A2065838). The contribution made by Joon-Young Hur was supported by the KIPA (basic research 2012-27).

\section{ORCID}

Min-Hyu Kim (D) http://orcid.org/0000-0001-8078-0526 


\section{References}

Andrew, S. A., \& Kendra, J. M. (2012). An adaptive governance approach to disaster-related behavioral health services. Disasters, 36(3), 514-532.

Baltrusaitis, J. (2020). Top 10 countries and cities by number of CCTV cameras. Precise Security. https://www.aithority.com/news/top-10-countries-and-cities-by-number-of-cctv-cameras/

Brunner, R. D., Steelman, T. A., Coe-Juell, L., Cromley, C. M., Tucker, D. W., \& Edwards, C. M. (2005). Adaptive governance: Integrating science, policy, and decision making. Columbia University Press.

Cairney, P. (2016). The politics of evidence-based policy making. Springer.

Chaffin, B. C., Gosnell, H., \& Cosens, B. A. (2014). A decade of adaptive governance scholarship: Synthesis and future directions. Ecology and Society, 19(3), 56-68.

Chaffin, B. C., \& Gunderson, L. H. (2016). Emergence, institutionalization and renewal: Rhythms of adaptive governance in complex social-ecological systems. Journal of Environmental Management, 165(1), 81-87.

Folke, C., Hahn, P., \& Norberg, J. (2005). Adaptive governance of social-ecological systems. Annual Review of Environmental Resources, 30, 441-473.

Holling, C. S., \& Gunderson, L. H. (2002). Panarchy: Understanding transformations in human and natural systems. Island Press.

Hong, S., \& Lee, S. (2018). Adaptive governance and decentralization: Evidence from regulation of the sharing economy in multi-level governance. Government Information Quarterly, 35(2), 299-305.

Hundt, D. (2015). Neoliberalism, the developmental state and civil society. Asian Studies Review, $39(3), 466-482$.

Janis, I. L. (1972). Victims of groupthink: A psychological study of foreign-policy decisions and fiascoes. Houghton Mifflin.

Janssen, M., \& van der Voort, H. (2016). Adaptive governance: Toward a stable, accountable and responsive government. Government Information Quarterly, 33(1), 1-5.

Nelson, R., Howden, M., \& Smith, M. S. (2008). Using adaptive governance to rethink the way science supports Australian drought policy. Environmental Science \& Policy, 11(7), 588-601.

OECD. (2020). Doctors' consultations (indicator). https://www.oecd-ilibrary.org/social-issuesmigration-health/doctors-consultations/indicator/english_173dcf26-en

Ostrom, E. (1999). Coping with tragedies of the commons. Annual Review of Political Science, 2(1), 493-535.

Scholz, J. T., \& Stiftel, B. (2010). Adaptive governance and water conflict: New institutions for collaborative planning. Routledge.

Schwak, J. (2016). Branding South Korea in a competitive world order: Discourses and dispositives in neoliberal governmentality. Asian Studies Review, 40(3), 427-444.

Weible, C., Nohrstedt, D., Cairney, P., Carter, D. P., Crow, D. A., Durnová, A. P., Heikkila, T., Ingold, K., McConnell, A., \& Stone, D. (2020). COVID-19 and the policy sciences: Initial reactions and perspectives. Policy Sciences, 53, 225-241.

Weiss, L., \& Thurbon, E. (2020). Developmental state or economic statecraft? Where, why and how the difference matters. New Political Economy. https://doi.org/10.1080/13563467.2020. 1766431

Yang, A. (2020, 21 May). South Korea's foreign minister Kang Kyung-wha: “We're not going back to life pre-COVID". ABC News. abcn.ws/2XnLxS8

You, M. (2020, 20 May). Four months of COVID-19 in terms of disaster psychology and social risk perception. Paper presented at the $13^{\text {th }}$ National Policy Forum on "COVID-19 pandemic, South Korea's responses and challenges”. Seoul National University, Seoul. 